\title{
Broadband polymer microstructured THz fiber coupler with downdoped cores
}

Nielsen, Kristian; Rasmussen, Henrik K.; Bang, Ole; Jepsen, Peter Uhd

Published in:

35. International Conference on Infrared, Millimeter, and Terahertz Waves

Link to article, DOI:

10.1109/ICIMW.2010.5612709

Publication date:

2010

Document Version

Publisher's PDF, also known as Version of record

Link back to DTU Orbit

Citation (APA):

Nielsen, K., Rasmussen, H. K., Bang, O., \& Jepsen, P. U. (2010). Broadband polymer microstructured THz fiber coupler with downdoped cores. In 35. International Conference on Infrared, Millimeter, and Terahertz Waves IEEE. https://doi.org/10.1109/ICIMW.2010.5612709

\section{General rights}

Copyright and moral rights for the publications made accessible in the public portal are retained by the authors and/or other copyright owners and it is a condition of accessing publications that users recognise and abide by the legal requirements associated with these rights.

- Users may download and print one copy of any publication from the public portal for the purpose of private study or research.

- You may not further distribute the material or use it for any profit-making activity or commercial gain

- You may freely distribute the URL identifying the publication in the public portal 


\title{
Broadband polymer microstructured $\mathrm{THz}$ fiber coupler with down- doped cores
}

\author{
Kristian Nielsen ${ }^{\mathrm{a}}$, Henrik K. Rasmussen ${ }^{\mathrm{b}}$, Ole Bang ${ }^{\mathrm{a}}$, and Peter Uhd Jepsen ${ }^{\mathrm{a}}$ \\ ${ }^{a}$ DTU Fotonik, Technical University of Denmark \\ ${ }^{b}$ DTU Mekanik, Technical University of Denmark
}

\begin{abstract}
We demonstrate a broadband $\mathrm{THz}$ directional coupler based on a dual core photonic crystal fiber (PCF) design with mechanically down-doped core regions. For a center frequency of $1.3 \mathrm{THz}$ we demonstrate a bandwidth of $0.65 \mathrm{THz}$.
\end{abstract}

\section{INTRODUCTION AND BACKGROUND}

$\mathrm{W}$ aveguides for terahertz $(\mathrm{THz})$ radiation have attracted widespread attention in recent years ${ }^{1}$ as the promise of efficiently delivering and confining the $\mathrm{THz}$ radiation is one that offers many applications. Much work is still at hand before the waveguides will deliver on that promise. However as the waveguides increase in quality, the next step is to make functional components based on such waveguides. Here we present the first broadband directional fiber coupler working in the $\mathrm{THz}$ regime.

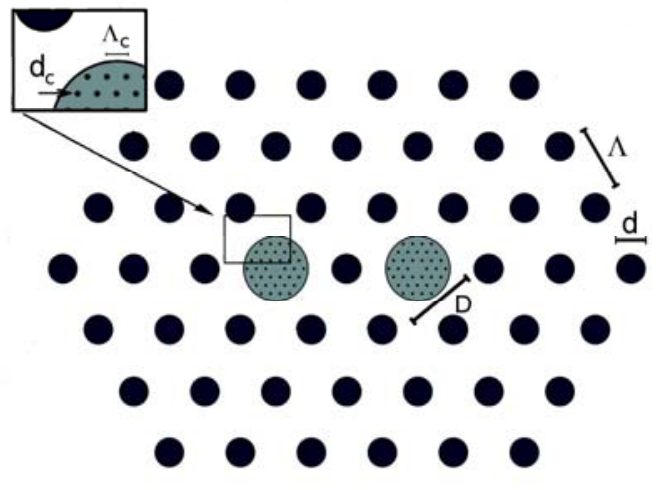

Figure 1: Cross section of the directional coupler. Black regions indicate air holes, the gray regions represent the cores with mechanical down-doping of the effective index.

The broadband functionality is achieved by down-doping the refractive index of the cores of a dual core photonic crystal fiber (PCF). Down-doping is usually carried out by chemical modification, but here we suggest a mechanical down doping. By introducing a subwavelength hole structure in the twin cores, very fine control over the down-doping is achieved. The down-doped cores experience mode field diameter minima and thereby also frequency ranges of constant coupling lengths as suggested by Lægsgaard $e t a l^{2}$

\section{RESULTS}

The generic fiber design is shown in Figure 1. Here we will focus on a fiber with a pitch $(\Lambda)$ of $750 \mu \mathrm{m}$ and a hole to pitch ratio $(\mathrm{d} / \Lambda)$ of 0.4 . This choice allows us to focus on the size of the doped region and the level of doping. The dual core fiber will support two degenerate fundamental modes. For each polarization there exists one even and one odd mode. The difference in propagation constant between the even and the odd modes gives the coupling length. Since the two modes are degenerate there is a single coupling length associated with both polarizations.

The coupling length is the length required before achieving a $\pi$ phase change between the modes in the two cores. The coupling length is given by: $L_{c}=\pi /\left(\beta_{\mathrm{e}}-\beta_{\mathrm{o}}\right)$, where $\beta_{\mathrm{e}}$ and $\beta_{\mathrm{o}}$ are the propagation constants for the even and odd modes respectively.

The refractive index of the core modes are calculated numerically using the MPB software package ${ }^{3}$. Because of the modified cores of the fiber there will be a broad frequency range where the coupling length is relatively constant. A fiber section with half the coupling length we will thus constitute a broadband 50/50. We define the bandwidth of the coupling as the range where the coupling ratio is constant to within $+/-5 \%$.

We now consider a fiber device that is $18.1 \mathrm{~cm}$ long and has a micro-structured core, where the pitch of the core $\left(\Lambda_{\mathrm{c}}\right)$ is $78.75 \mu \mathrm{m}$ and the hole to pitch ratio in the core is 0.145 . Such a device will have a 50/50 coupling bandwidth of $0.65 \mathrm{THz}$ centered at 1.3 THz. The bandwidth is shown in Figure 2, where the bandwidth of a coupler with undoped cores as well as the bandwidth of a coupler with larger core pitch is shown. In both the down doped cases the $d_{c} / \Lambda_{c}$ is 0.145 .

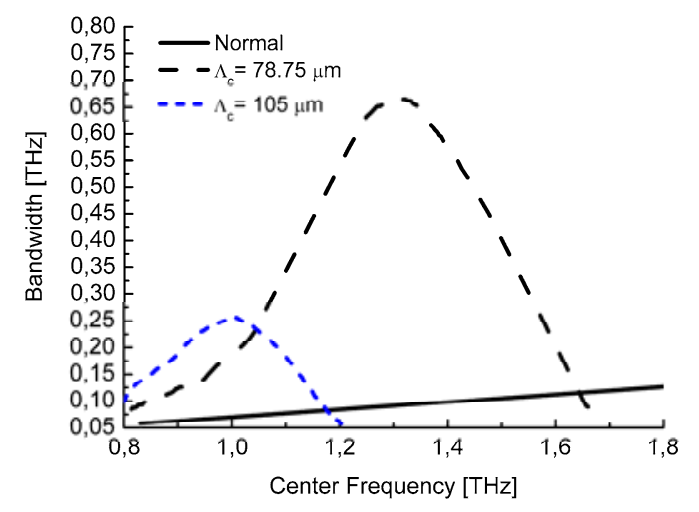

Figure 2: Bandwidth of the directional coupler for a normal (undoped) coupler and for two choices of core pitch $\Lambda_{c}$

\section{REFERENCES}

[1] K. Nielsen, Henrik K. Rasmussen, Ole Bang, and Peter Uhd Jepsen, Opt. Express 17, 8592 (2009)

[2] J. Lægsgaard, Ole Bang, and Anders Bjarklev, Opt. Lett. 29, 2473 (2004)

[3] Steven G. Johnson and J. D. Joannopoulos, Opt. Express 8, 173 (2001), 